SHORT REPORT

\title{
Mercury contamination in reproductive age women in a Caribbean island: Vieques
}

\author{
Carmen Ortiz-Roque, Yadiris López-Rivera
}

J Epidemiol Community Health 2004;58:756-757. doi: 10.1136/jech.2003.019224

$\mathrm{T}$ eratogenic amounts of mercury can avidly cross human placental barrier causing permanent neurological impairment to the developing fetus. A warning, from the USA Food and Drug Administration, advising reproductive age women to limit fish consumption, highlights the importance of this contaminating route. ${ }^{1}$ Internal mercury exposure in fish consuming communities in the Caribbean Basin has not been evaluated. Our study assessed mercury internal exposure for reproductive age women in a heavily industrialised area of north eastern Puerto Rico (NEPR) and its island municipality of Vieques, spared from industrial activities.

\section{METHODS}

Women of ages 16-49, attending their primary physician, were invited to participate. The study was free to all participants. The general population of Vieques was informed of the study dates. Bonafide residence in towns from San Juan to Ceiba, for the NEPR cohort, or Vieques, during the year preceding the hair sample was confirmed. Women with chemically treated hair during the three months preceding the study were excluded. Demographic, medical, nutritional, occupational, religious, residential, and cosmetic information was individually obtained. Completion of the study's questionnaire and consent forms were prerequisites for hair sampling.

The study was in compliance with the Code of Professional Ethic Canons of the Board of Medical Examiners of Puerto Rico. During the period from 2000 to 2002, a proximal scalp hair sample of 1.5-2 cm was obtained from each participant. NEPR and Vieques samples were analysed simultaneously by inductively coupled plasma mass spectrometry and inductively coupled plasma atomic emission spectroscopy at either of two facilities. Both laboratories are licensed by the USA Clinical Laboratory Improvement Act. ${ }^{2}$

The margin of exposure (MOE) to mercury, 12 parts per million (ppm)/90th centile hairs $(\mathrm{Hg})$, defined unsafe population exposure. ${ }^{3}$ Reference dose analysis (RfD), percentage of women exceeding the estimated daily mercury consumption that is likely to be deleterious during a lifetime for humans, was estimated for each cohort. ${ }^{4}$ The World Health Organisation criterion for hair mercury concentrations associated with adult mercurial toxicity $(>10.0 \mathrm{ppm})$ was used to define adult disease levels. ${ }^{5}$ Parametric variables were compared by unpaired $t$ test. Non-parametric variables were analysed by Mann-Whitney's test. Spearman correlations were performed.

\section{RESULTS AND DISCUSSION}

Reproductive age women residing in the NEPR were compared with the analogous Vieques cohort (table 1). No difference was found in their average age. The participation rate was $20 \%$ for NEPR and $31 \%$ for Viequenses. The mean hair $(\mathrm{Hg})$ for the Vieques cohort was $4.4(0.5-8.9)$ while that of NEPR was $0.4(0.3-0.5)$. Vieques' cohort also had higher mercury 90th centiles than the NEPR counterpart $(8.9 v 1.0)$ and than those reported for the United States 1.4 (0.9-1.7). Three of the 41 women of reproductive age in Vieques had hair $(\mathrm{Hg})$ higher than $12.0 \mathrm{ppm}$ (101.3, 25.3, and $15.4 \mathrm{ppm})$. None of the 45 women from NEPR nor the702 women studied in the USA had such high mercury levels. ${ }^{3}$

The margin of exposure to mercury was unsafe for women of reproductive age in Vieques, 1.3, but was safe for women of reproductive age in NEPR, 12. Seafood consumption averaged 4.9 and 2.8 times per week for the Vieques and NEPR cohorts, respectively. Hair mercury concentration correlated positively with weekly consumption of local seafood for Viequenses (Spearman correlation 0.47, $\mathrm{p}=0.002$ ).

Mercury concentrations did not correlate with age or BMI for either cohort. Occupational, medicinal, cosmetic, and religious practices failed to reveal other possible sources of mercury contamination. Based on hair $(\mathrm{Hg})$, mercury RfD was exceeded by $26.8 \%$ of the Vieques and $6.6 \%$ of the NEPR cohort.

Mercury is among the 102 violations to effluent water quality parameters committed by the US Navy in the coast of Vieques. ${ }^{6}$ No other source of mercury contamination has been identified in that island. The volatility of mercuric sublimate, its incorporation, biomagnification, and persistence in aquatic habitats and Viequenses dependence on marine protein, makes human mercury contamination feasible.

Abbreviations: NEPR, north eastern Puerto Rico; RfD, reference dose analysis; $M O E$, margin of exposure

Table 1 Mercury concentrations, seafood consumption frequency, and exposure assessment for reproductive age women in Vieques and Puerto Rico (2000-2002)

\begin{tabular}{|c|c|c|c|c|c|c|c|c|c|c|}
\hline & \multirow[b]{2}{*}{ Number } & \multirow[b]{2}{*}{ Age (SE) } & \multirow[b]{2}{*}{ BMI* } & \multirow{2}{*}{$\frac{(\mathrm{Hg})}{\text { Median } 9 \mid}$} & \multirow{2}{*}{$\frac{\text { (ppm) }}{90 \text { th centile }}$} & \multirow{2}{*}{$\begin{array}{l}\text { Margin of } \\
\text { exposure† }\end{array}$} & \multicolumn{3}{|c|}{ Seafood consumption‡ } & \multirow{2}{*}{$\begin{array}{l}\text { \% Of women } \\
\text { exceeding RfD§ }\end{array}$} \\
\hline & & & & & & & Total * & Local ${ }^{* \star}$ & Local fish & \\
\hline Vieq & 41 & 31.8 & 25 & 0. & 8.96 & 1.3 & 4. & 2. & 1 & 26.8 \\
\hline NE Puerto Rico & 45 & $29.9(1.2)$ & $29.4(1.2)$ & 0.38 & 1 & 12 & 2.8 & 1.1 & 0.7 & 6.6 \\
\hline$U_{S A^{34}}$ & 702 & N/Att & N/A & 0.20 & 1.4 & 8.6 & N/A & N/A & N/A & 7 \\
\hline
\end{tabular}

*Arithmetic mean significant $(p<0.05) ; † M O E<10$ is unsafe mercury exposure; łaverage weekly frequency of seafood consumption; $\S R F D=0.1 \mu \mathrm{gg} / \mathrm{kg}$ per day; Imedians significant $(p<0.05)$; ${ }^{* *}$ arithmetic mean significant $(p<0.01)$; ††data not available. 


\section{Key point}

Women of reproductive age in the island of Vieques were exposed to mercury concentrations that are unsafe to their developing fetus.

This study may have some limitations. The participation rate was low for both groups. Unfortunately, the general population in Puerto Rico (and its Vieques island) is unaware of fish consumption as a possible route for mercury contamination. Unfamiliarity with hair testing, aesthetic reasons, and unwillingness to complete a questionnaire was mentioned by non-participants. Over representation of people concerned about contamination can always be present.

Selection bias in this cohort study could have occurred if disease status (mercury hair concentration) was known at the time of entering the study. As hair mercury determinations were done months after hair sampling, the participants and the researchers were not cognisant of the results.

\section{ACKNOWLEDGEMENTS}

We thank Dr J Ortiz-Roque for his toxicological perspective and critical revision and to $\mathrm{Dr} \mathrm{T}$ Schettler for his meticulous critical review. The collaboration of members of the College of Physicians and Surgeons of Puerto Rico is deeply appreciated.

\section{CONTRIBUTORS}

Carmen Ortiz-Roque, MD, MPH, MS was responsible for design, funding, data collection, analysis, drafting, and approval of the final version. Yadiris López-Rivera, CT, MS (c) was responsible for design, interpretation, data analysis, and final drafting.

\section{Authors' affiliations}

C Ortiz-Roque, Y López-Rivera, GINECO, San Juan, Puerto Rico

\section{Policy implications}

Isolated civilian populations in the proximity of atypical industries, like the military, can be at increased risk of mercury exposure.

Funding: GINECO, a non-profit organisation dedicated to reproductive research and health education in the Caribbean.

This study was completed with the collaboration of members of the College of Physicians and Surgeons of Puerto Rico, GINECO and the first author.

Correspondence to: Dr C Ortiz-Roque, PO Box 9023930, San Juan, Puerto Rico 009023930; yadirislopez@hotmail.com

Accepted for publication 18 December 2003

\section{REFERENCES}

1 FDA CFSAN. Consumer advisory: an important message for pregnant women and women of childbearing age who may become pregnant about the risks of mercury in fish. Washington: US Center for Safety and Applied Nutrition, US Food and Drug Administration, 2001.

2 Shamberger RJ. Validity of hair mineral testing. Biol Trace Elem Res 2002;87:128.

3 CDC. Blood and hair mercury levels in young children and women of childbearing age-United States, 1999. MMWR 2001 March 2;50:1403.

4 EPA. Mercury study report to Congress, Vol 4. Washington, DC: Office of Air Quality Planning and Standards and Office of Research and Development, Environmental Protection Agency; an Assessment of Exposure to Mercury in the United States, 1997.

5 World Health Organisation. Methyl mercury. Environmental health criteria 101. Geneva: WHO, 1990.

6 EPA. Discharge monitoring report for the Atlantic Fleet weapons training facility. New York, NY: US Environmental Protection Agency Region II, Caribbean Field Office, 1999. 